\title{
Effect of Mercury on Seed Germination, Growth Parameters and Biochemical Characteristics of Indian Mustard (Brassica juncea L.) Cultivars
}

\author{
Ajay Kumar* and S. S. Sharma \\ Department of Biosciences, Himachal Pradesh University, Shimla-171005, India \\ *Corresponding author
}

\begin{tabular}{l} 
Ke y w o r d s \\
$\alpha$-amylase, \\
Brassica juncea, \\
CAT, Mercury, \\
Seed germination, \\
SOD \\
\hline Article Info \\
\hline $\begin{array}{l}\text { Accepted: } \\
\text { 12 March } 2020 \\
\text { Available Online: } \\
10 \text { April } 2020\end{array}$ \\
\hline
\end{tabular}

The effect of elevated concentrations of mercury on seed germination and seedlings growth responses of three Brassica juncea L. cultivars, namely Varuna, Kranti, and Pusa Jai Kisan. was evaluated. The mercury concentrations $(0,25,50,100,200 \mu \mathrm{M})$ suppressed seed germination significantly in concentration dependent manner and differentially among the cultivars. The inhibition due to $\mathrm{Hg}$ was much greater after one day of treatment with lowest suppression in cv. Varuna than others. In seedling growth performance, Root growth was inhibited quite strongly, with highest and lowest inhibition in cv. Pusa Jai Kisan and Varuna respectively. Shoot growth was not affected much in all cultivars. The seedling fresh weight in general reduced. Activity of $\alpha$-amylase and MDA content were differentially altered among all cultivars studied. Also, significant increase in $\alpha$-amylase activity was observed in cv. Varuna when compared with other cultivars. The CAT activity was marginally promoted by $\mathrm{Hg}$ in cultivar Pusa Jai Kisan and Kranti. The SOD activity was not strongly influenced due to $\mathrm{Hg}$ treatments. The results seem to be a consequence of differential sub cellular $\mathrm{Hg}$ distribution and antioxidative defence resulting in constitutive activity of SOD and CAT. Findings have implication in establishment of seedlings in mercury enriched soils and in turn of phytoremediation.

\section{Introduction}

Mercury $(\mathrm{Hg})$ is among the highly toxic nonessential Heavy metals (HMs) and its dispersion in the environment is considered as a serious environmental problem due to its persistent character (Liu et al., 2011). Global mercury release increased remarkably with industrialization. (Kolker et al., 2006) The atmospheric $\mathrm{Hg}$, which undergoes oxidation reaction and deposits to the ground, increases the abundance of $\mathrm{Hg}$ in soil and water (Lindberg et al., 2007).

In addition to this, a considerable amount of $\mathrm{Hg}$ is introduced into agricultural soils as fertilizers, fungicides and pesticides. In soil mercury exist in many elemental forms among which $\mathrm{Hg}^{2+}$ is a predominant and bioavailable forms for plants (Han et al., 
2006). Mercury is readily taken up by roots that accumulate most of it with a part being translocated to leaves, flowers and other developmental tissues (Sierra et al., 2009). Hg import in to root cells is possibly through Fe, $\mathrm{Cu}$, or $\mathrm{Zn}$ transporters/channels (Esteban et al., 2008). High concentrations of $\mathrm{Hg}$ cause reduction in seedling growth, photosynthesis, nutrient uptake, transpiration rate, water uptake, chlorophyll synthesis (Boening, 2000), germination (Wang et al., 2003) and respiration (Patra et al., 2004), all contributing to seed toxicity and productivity loss.

Plants employ multiple strategies for cellular management of toxic metal concentrations (Sharma and Dietz 2006). They range from cytosolic chelation of heavy metal ions through different ligands to sequestration in to different cellular compartments. Heavy metals (HMs) stressed plants often exhibit enhanced level of lipid peroxidation. Strongly redox ions such as $\mathrm{Cu}^{2+}$ and $\mathrm{Hg}^{2+}$ are capable of initiating the peroxidation of lipids components of membrane system.

Data from diverse biochemical and metabolic approaches have established a firm link between cellular redox imbalance and HMs toxicity (Sharma and Dietz 2009). HMs could alter the catalytic functions of enzymes through their interaction with - $\mathrm{SH}$ groups, phosphate groups, and the replacement of essential ions that would alter the protein conformation (Patra et al., 2004).

HMs toxicity has been reported to reduce the radical emergence via enhanced protein and carbohydrate contents, affecting the activity of peroxidases (POX) and polyphenol oxidases (PPO).

HMs supresses the oxidizing ability of roots resulting in overall lowering of carbohydratemetabolizing enzymes- $\alpha$-amylases, $\quad \beta$ - amylases, acid invertases and acid phosphatases (Singh et al., 2011). HMs induce oxidative stress by stimulating the generation of ROS and concomitantly suppressing the cellular antioxidative defence (Sharma and Dietz 2006). Hg has been reported to both promote and suppress the activity of antioxidative enzymes (Pätsikkä et al., 2002)by interfering and altering non enzymatic antioxidants like glutathione (GSH) and nonprotein thiols (NPSH) and also the enzymatic antioxidants like superoxide dismutase (SOD), ascorbate peroxidase (APX), and glutathione reductase (GR) (Ortega-Villasante et al., 2005). Hg has been demonstrated to induce expression of genes encoding SOD (superoxide dismutase), POD (peroxidase), and CAT (catalase) (Neumann et al., 1997).

Phytoremediation is a green technology by which plant remove heavy metals from the contaminated soils (Kumar and Thakur 2019). Plants have species specific differences with regards to the tolerance to diverse HMs. Certain metal hyper accumulator plant species possess the ability to accumulate extraordinarily high concentration of specific metals with a low toxic influence. These plants are central to realization of phytoremediation technology (Pilon-Smits, 2005).

Several members of Brassicaceae have shown the potential for hyper accumulation, Since Indian mustard (Brassica juncea L.) has higher biomass and faster growth rates compared to other hyper accumulator plants, present study focuses to determine seed germination and seedling growth responses to surplus mercury concentration. With a view to reveal the likely basis of cultivar specific differences and to get insight in to the possible mechanism how plants make less severe to the mercury stress certain metabolic aspects have also been studied. 


\section{Materials and Methods}

\section{Seed source}

Seeds of Indian mustard (Brassica juncea L.) cultivarKranti were procured from G.B. Pant University of Agriculture and Technology, Pantnagar (Uttarakhand) while Seeds of cultivar Pusa Jai Kisan and Varuna were procured from Indian Agricultural research institute (IARI), New Delhi.

\section{Seed germination and seedling growth performance}

Uniform seeds of all the cultivars were surface sterilized with $0.1 \% \mathrm{HgCl}_{2}$ for 5 minutes followed by thorough washing with distilled water. They were soaked in solutions $(10 \mathrm{ml})$ of different concentration of $\mathrm{Hg}(25$, $50,100,200 \mu \mathrm{M}$ ) in the form of $\mathrm{HgCl}_{2}$ for 24 hours. Seeds simultaneously soaked in distilled water constituted the control. Thereafter, the seeds were transferred to Petri plates lined with double layer of Whitman's filter paper made wet with $2 \mathrm{ml}$ of respected solutions of $\mathrm{Hg}$ concentrations. The petridishes were placed in plant growth chamber (Sanyu, Japan) at $25 \pm 2{ }^{0} \mathrm{C}$ under continuous illumination (PAR: $40 \mu \mathrm{mol} \mathrm{m} \mathrm{m}^{-2}$ $\left.{ }^{1}\right)$ for seed germination and seedling growth. The emergence of $2-5 \mathrm{~mm}$ radicle was taken as seed germination (ISTA, 1966). Seed germination was recorded for three days of incubation. After 6-day treatment, the seedling growth in terms of root length, shoot length and seedling fresh weight was measured.

\section{$\alpha$-amylase activity}

$\alpha$-amylase activity was determined according to the method of Filner and Varner (1967). Seeds treated with $\mathrm{Hg}$ were used to extract the crude enzyme by homogenizing seed tissue $(100 \mathrm{mg}$ ) with $2 \mathrm{ml}$ chilled $50 \mathrm{mM}$ Tris- $\mathrm{HCl}$ buffer ( $\mathrm{pH}$ 7.2) in chilled pestle and mortar.
The homogenate was centrifuged at 10,000 rpm for $10 \mathrm{~min}$ at $4^{\circ} \mathrm{C}$ and supernatant (crude enzyme) collected. $1 \mathrm{ml}$ of enzyme was incubated with $1 \mathrm{ml}$ of substrate $(0.15 \%$ Starch; $0.2 \mathrm{mM} \mathrm{CaCl}_{2}$ ) for 10 minute at $25 \pm$ $2^{0} \mathrm{C} .3 \mathrm{ml}$ of IKI reagent $(0.6 \%$ Iodine in $6 \%$ $\mathrm{KI} ; 1 \mathrm{ml}$ of this stock solution made to $50 \mathrm{ml}$ with $0.05 \mathrm{~N} \mathrm{HCl}$ ) was added in the reaction mixture and incubated for $10 \mathrm{~min}$. Absorbance was read at $620 \mathrm{~nm}$. In control, IKI was added prior to the addition of enzyme. Total amount of starch degraded was determined with the help of a calibration curve prepared with starch.

\section{Measurement of lipid peroxidation}

Lipid peroxidation accumulated as melondialdehyde content (MDA) was estimated following the method given by Dhindsa et al., (1981). In brief, the seed tissue ( $\pm 100 \mathrm{mg}$ ) was homogenized with $2 \mathrm{ml} 0.1 \%$ TCA (trichloroacetic acid). The homogenate was centrifuged at 10,000 rpm for $10 \mathrm{~min}$ and supernatant collected. $1 \mathrm{ml}$ supernatant was reacted with $2 \mathrm{ml} 0.05 \%$ thiobarbituric acid (TBA) in 20\% trichloroacetic acid (TCA) and mixture heated at $95^{\circ} \mathrm{C}$ in a water bath for 45 minutes. The reaction was terminated by rapidly cooling the reaction mixture in ice for 5 minutes. Absorbance was read at $532 \mathrm{~nm}$. Correction of measurements for unspecific turbidity were performed by subtracting absorbance at $600 \mathrm{~nm}$. MDA contents were determined by using the extinction coefficient of $155 \mathrm{mM}^{-1} \mathrm{~cm}^{-1}$ (Heath and Packer 1968).

\section{Superoxide dismutase (SOD) activity}

The activity of SOD (superoxide dismutase) was measured according to Beauchamp and Fridovich, 1971 method. Extraction buffer used was $100 \mathrm{mM}$ K-Phosphate (pH-7.0). Reaction mixture contained $670 \mu \mathrm{l}$ assay buffer K-Phosphate buffer (100 mM, pH 7.8), $100 \mu \mathrm{l}$ riboflavin $(130 \mu \mathrm{M}), \quad 100 \mu \mathrm{l}$ 
Methionine (13 mM), $100 \mu \mathrm{l}$ NBT (1.26 $\mathrm{mM})$, and $30 \mu \mathrm{l}$ enzyme extract. The reaction was illuminated for 8 minute and absorbance read at $560 \mathrm{~nm}$ against distilled water. A 50\% reduction in absorbance (as compared to blank) was taken as one-unit activity.

\section{Catalase (CAT) activity}

Treated seed tissue was homogenized with $100 \mathrm{mM}$ HEPES-NaOH buffer (pH-7.4) containing $5 \mathrm{mM}$ ascorbate, and the homogenate was centrifuged. The supernatant was used for assay of catalase. Catalase activity was assayed polarographically using a Clarke-type $\mathrm{O}_{2}$ electrode (Hansatech, UK). The electrode was calibrated using sodium dithionite. The reaction mixture contained $890 \mu \mathrm{l}$ HEPES-KOH buffer100 mM (pH 7.4), $10 \mu \mathrm{l}$ of enzyme extract, and $100 \mu \mathrm{l} \mathrm{H}_{2} \mathrm{O}_{2}$ (100 $\mathrm{mM})$. The reaction was initiated by adding the enzyme extract at last. The enzyme activity was calculated from the slopes recorded on graph paper by using the value of dissolved oxygen at $25^{\circ} \mathrm{C}$.

All the data were recorded in triplicates. Values were then used to perform statistical analysis and create graphics in Microsoft Excel 2016. Means \pm standard deviation, Standard error of the mean were calculated for all measurements.

\section{Results and Discussion}

\section{Seed germination and seedling growth}

Elevated concentrations of $\mathrm{Hg}$ suppressed the seed germination in all three cultivars. After one day of incubation highest $\mathrm{Hg}$ concentration $(200 \mu \mathrm{M})$ showed maximum inhibition (Fig. 1) in Pusa Jaikisan (75\%) followed by Kranti (65\%) and Varuna (55\%). In cultivar Kranti, the lower $\mathrm{Hg}$ concentrations $(25 \mu \mathrm{M})$ seems to be marginally promotory for seed germination but observed promotion was statistically insignificant. The magnitude of $\mathrm{Hg}$ induced inhibition was declined after one day with a considerable recovery after 3 days of incubation. After three days, the seed germination inhibition was reduced to 0,20 and $5 \%$, respectively in three cultivars.

On the basis of seed germination cultivar Varuna appeared to be the most tolerant to mercury toxicity. Seedling growth was inhibited by mercury in all cultivars with distinct organ and cultivar specific differences. $\mathrm{Hg}$ induced Suppression of root length was far greater than that of shoot length which was not affected much by $\mathrm{Hg}$ treatment (Fig. 2).

Lowest inhibition of root length due to $\mathrm{Hg}$ treatment occurred in cultivar Pusa Jai Kisan across all concentrations followed by that in cultivar Kranti and Varuna. Root growth inhibition due to $100 \mu \mathrm{M} \mathrm{Hg}$ was 16, 23 and $34 \%$ in cultivars Pusa Jai Kisan, Kranti and Varuna, respectively. These values increased to 29,38 and $46 \%$, respectively in case of 200 $\mu \mathrm{M} \mathrm{Hg}$ (Fig. 2a). Despite of reduction in root length, the Shoot length is not affected much.

These results show strong organ specific differences (Fig. 2b). The seedling fresh weight was in general reduced due to $\mathrm{Hg}$ treatment. But there was no specific pattern of change in different cultivars. Thus seedling fresh weight was reduced by 10,11 and $28 \%$ at $100 \mu \mathrm{M}$ of $\mathrm{Hg}$ in cultivars Varuna, Kranti and Pusa Jai Kisan, respectively.

However, at $200 \mu \mathrm{M} \mathrm{Hg}$ these values became 24, 6 and 20\%, respectively (Fig. 2c). Taken together data suggest cv. Pusa Jaikisan and Varuna to be the most tolerant to root length and seedling Fresh weight respectively. In order to find an explanation for $\mathrm{Hg}$ induced suppression of seed germination and seedling growth of Brassica juncea cultivars certain 
metabolic parameters were measured in the seeds treated with 50 and $200 \mu \mathrm{M} \mathrm{Hg}$ for $24 \mathrm{~h}$.

\section{$\alpha$-amylase activity}

The activity of $\alpha$-amylase, responsible for hydrolysis of starch and necessary for availability of mobilizable carbohydrates was evaluated. There were strong cultivars specific differences in the response of $\alpha$ amylase activity to the applied $\mathrm{Hg}$ concentrations. Thus the activity of $\alpha$-amylase in the seeds of cv. Varuna was not inhibited by $\mathrm{Hg}$, instead promotion of activity was observed at both the $\mathrm{Hg}$ concentrations.

In contrast, the $\alpha$-amylase activity was inhibited due to $\mathrm{Hg}$ treatment in cv. Kranti and Jai Kisan. The magnitude of inhibition was greater in case of cultivar Jai Kisan than that in cv. Kranti. Thus the $\alpha$-amylase activity in case of cv. Kranti inhibited by 24 and 30\% due to 50 and $200 \mu \mathrm{M} \mathrm{Hg}$, respectively. This inhibition was 40 and $76 \%$ respectively in case of cv. Jai Kisan (Fig. 3a).

\section{Lipid peroxidation}

Lipid peroxidation measured in terms of Malondialdehyde (MDA) contents in the seeds of Brassica juncea cultivars was differentially altered due to $\mathrm{Hg}$ treatment in different cultivars. Thus in cultivar Varuna MDA contents was substantially increased at both the concentrations of $\mathrm{Hg}$. An increase of 54 and $34 \%$ was noted at 50 and $200 \mu \mathrm{M} \mathrm{Hg}$, respectively.

However, in other two cultivars MDA contents were either not changed due to $\mathrm{Hg}$ or they were reduced. Thus in cultivar Kranti, MDA contents remained generally unchanged at $50 \mu \mathrm{M} \mathrm{Hg}$ but were reduced by $20 \%$ at 200 $\mu \mathrm{M} \mathrm{Hg}$. In contrast, in case of cultivar Jai Kisan MDA contents were reduced by $33 \%$ at $50 \mu \mathrm{M}$ but not changed at $200 \mu \mathrm{M} \mathrm{Hg}$ (Fig. $3 b)$.

\section{Superoxide dismutase and catalase activity}

In addition to the lipid peroxidation, the activity of two antioxidative enzymes namely superoxide dismutase (SOD) and catalase (CAT) were monitored in $\mathrm{Hg}$ treated seeds. The SOD activity was not strongly influenced due to $\mathrm{Hg}$ treatment. At $50 \mu \mathrm{M} \mathrm{Hg}$ SOD activity was promoted by 4 and $8 \%$ in cultivar Kranti and Varuna, respectively but was inhibited by $11 \%$ in case of cv. Jai Kisan.

At $200 \mu \mathrm{M} \mathrm{Hg}$ SOD activity was promoted to varying degree in different cultivars. Thus a promotion of 9, 28 and $15 \%$ was observed in cultivars Jai Kisan, Kranti and Varuna respectively (Fig. 4a). The CAT activity was marginally promoted by $\mathrm{Hg}$ in cultivar Jai Kisan and Kranti. The degree of promotion ranges from $2-12 \%$ in these cultivars. In contrast the CAT activity was suppressed due to $\mathrm{Hg}$ in case of cultivar Varuna. An inhibition of $30 \%$ was observed at both concentrations of $\mathrm{Hg}$ (Fig. 4b).

Seed germination was suppressed by $\mathrm{Hg}$ in a concentration dependent manner. $\mathrm{Hg}$ has inhibitory effects have been reported by many workers (Jeliazkova et al., 2003; Ling et al., 2010; Jagastheeswari and Ranganathan, 2012). The Hg- induced suppression of seed germination was evident only after one day of the treatment specially at highest $(200 \mu \mathrm{M})$ $\mathrm{Hg}$ concentration used where cv. Varuna proved significantly more tolerant to $\mathrm{Hg}$ than cultivars Kranti and Pusa Jaikisan.

The type and magnitude of HMs effects seed germination appeared to be determined by the degree of permeability of seed coat to HM ions in different species (Wierzbicka and Obidzińska, 1998). Apparently, Hg uptake by seeds occurred in this study that is evident from suppression of seed germination. However, it is not clear whether the differential seed germination suppression by 
$\mathrm{Hg}$ was related to differential $\mathrm{Hg}$ uptake as we have not measured the $\mathrm{Hg}$ contents of seed.

The root elongation growth parameter has been employed for the assessment of HM toxicity (Sharma and Dietz 2009) and for assigning the relative HM sensitivity / tolerance to different genotypes of a species. In the analysis of seedling growth performance marked organ specific differences in response to $\mathrm{Hg}$ were observed. Thus the root elongation growth was suppressed much more in case of all cultivars as compared to shoot elongation growth. Such differences are consistent with the retention of the bulk of metal ions in the roots (Jagastheeswari and Ranganathan, 2012; Thakur and Sharma, 2016).

Furthermore, the $\mathrm{Hg}$ induced root suppression was significantly lowest in case of cv. Pusa Jai Kisan then in others. Obviously, the $\mathrm{Hg}$ tolerance of different Brassica juncea cultivars varied depending upon the parameter considered. Thus on the basis of performance of seed germination cv. Varuna was significantly most tolerant while on the basis of root length inhibition cv. Pusa Jai Kisan was most tolerant.

It was interesting to note that despite strong suppression of root growth shoot growth remains generally unaffected in all the cultivars. $\mathrm{Hg}$ has inhibitory effect on shoot growth parameter is reported by many studies (Jagastheeswari and Ranganathan, 2012; Mondel et al., 2015). The lack of $\mathrm{Hg}$ effect on shoot growth in Brassica juncea in present study suggests a tolerance towards $\mathrm{Hg}$ through restricted root to shoot translocation at least at seedling stage. Our results of shoot growth parameters are consistent with the results of Rodríguez-Alonso et al., 2019 where no significant differences were observed among the $\mathrm{Hg}$ treatments on above- ground parts in Quercus ilex L. seedlings. Consequently, the seedlings are able to maintained photosynthetic functions even in the presence of $\mathrm{Hg}$ ions. The seedling fresh weight was in general reduced due to $\mathrm{Hg}$ treatment. But there was no specific pattern of change in different cultivars. Taken together data suggest cultivar Pusa Jaikisan and Varuna, significantly most tolerant to root length and seedling Fresh weight respectively.

The $\mathrm{Hg}$ induced root growth inhibition could also be explained on the basis of changes in hydrolytic enzymes and redox parameters. Activity of Enzyme $\alpha$-amylase responsible for breakdown of polysaccharide reserves was studied in seeds. The data concerning the $\alpha$ amylase activity suggest that the differential $\mathrm{Hg}$ tolerance in terms of seed germination performance was related to the differential effect of $\mathrm{Hg}$ on starch hydrolysis. The $\alpha$ amylase activity was not inhibited in most tolerant cv. i.e. Varuna but was inhibited in other cultivars. Besides, hydrolytic enzymes and redox metabolism $\mathrm{Hg}$ might have modified the $\mathrm{GA}_{3}$ levels necessary for induction of $\alpha$ - amylase activity and in turns the availability of mobilizable sugars (Sahu et al., 2012).

HMs induced phytotoxicity is often described among other reasons to the cellular redox imbalance (Schutzendubel and Polle, 2012; Sharma and Dietz, 2009). In response to membrane lipid peroxidation, specific cellular metabolic circumstances and repair capacities may promote cell survival or induce cell death through constitutive antioxidants defence systems or signalling pathways activation that regulates antioxidants proteins resulting in an adaptive stress response (Sharma and Kumar 2015). Accordingly, we have measured the lipid peroxidation, SOD and CAT activity in $\mathrm{Hg}$ treated seeds. The observed changes in these parameters in present study indicate that $\mathrm{Hg}$ imposed an oxidative stress to varying 
degrees in the seeds of these cultivars. Lipid peroxidation in terms of Malondialdehyde (MDA) contents in the seeds of Brassica juncea cultivars was differentially altered due to $\mathrm{Hg}$ treatment in all cultivars. Cultivar Varuna proved to be most tolerant than its counterparts to elevated $\mathrm{Hg}$ concentrations. Our findings of MDA increase in $\mathrm{Hg}$ treated seeds conform to those in barley (Sharma et al., 2004) under $\mathrm{Cd}$ exposure, tomato (Cho and Park 2000) under $\mathrm{Hg}$ exposure and Indian mustard (Thakur and Sharma 2016) under Ni exposure.

Superoxide dismutase (SOD) activity was not markedly affected in Varuna and Kranti but was significantly inhibited in cv. Jai Kisan so this finding seems to be in contrast to that of Cho and Park (2000) where the results showed a marked increase in SOD activity in the $\mathrm{Hg}$ treated tomato seedlings. The CAT activity was marginally promoted by $\mathrm{Hg}$ in cultivar Pusa Jai Kisan and Kranti. Under relatively low levels of SOD and CAT activity the ROS, such as superoxide anions and $\mathrm{H}_{2} \mathrm{O}_{2}$ will increase in concentration. This might account for the observed growth inhibition to some extent. In addition to this the differential $\mathrm{Hg}$ tolerance of the Brassica juncea cultivars might be related to the differences in subcellular allocation of $\mathrm{Hg}$ ions.
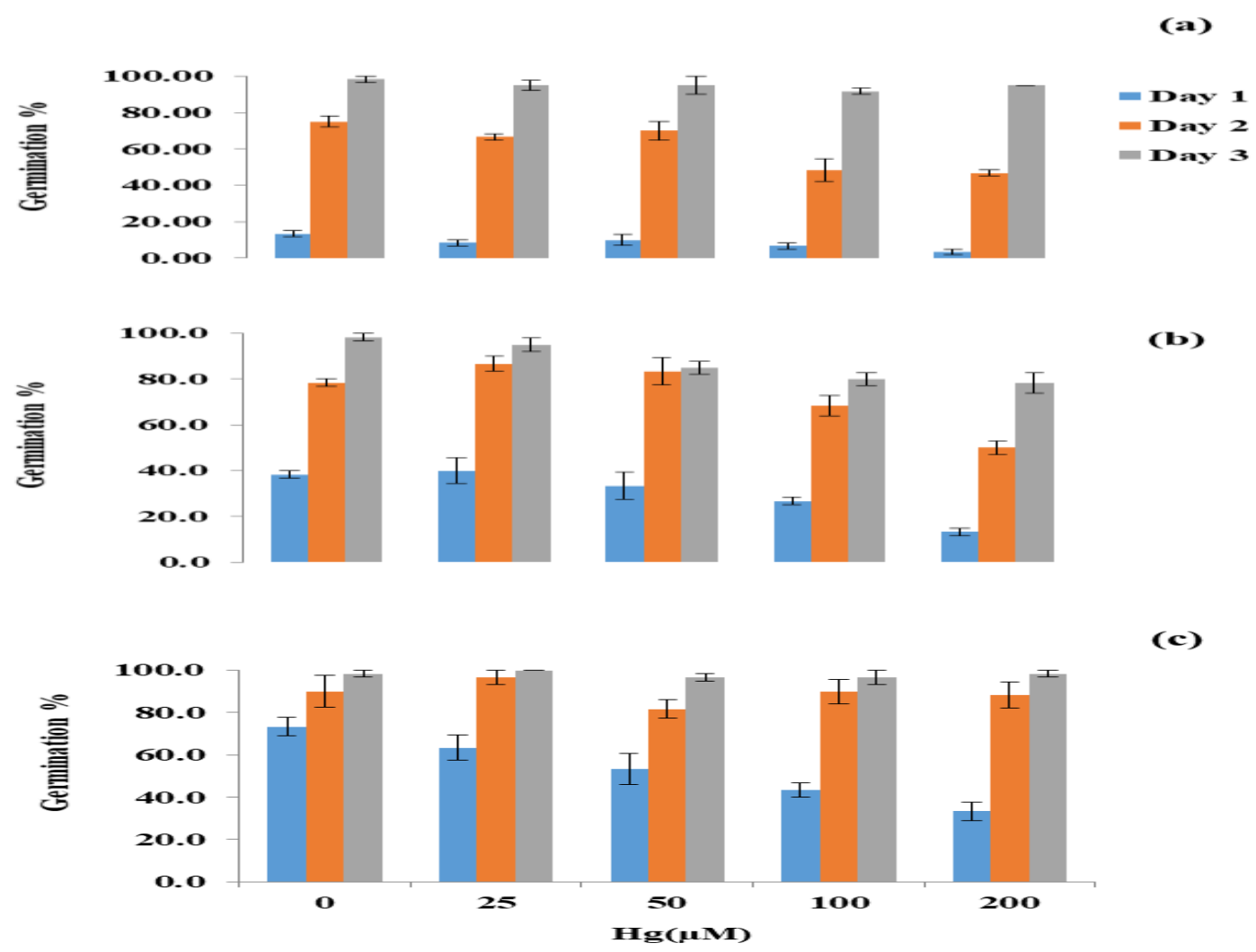

Fig.1 Time-course of seed germination of Brassica juncea cultivars, (a) Pusa Jai Kisan,

(b) Kranti, (c) Varuna as affected by Hg. Data are arithmetic means \pm S.E., $n=3$ (each replicate comprised 20 seeds) 


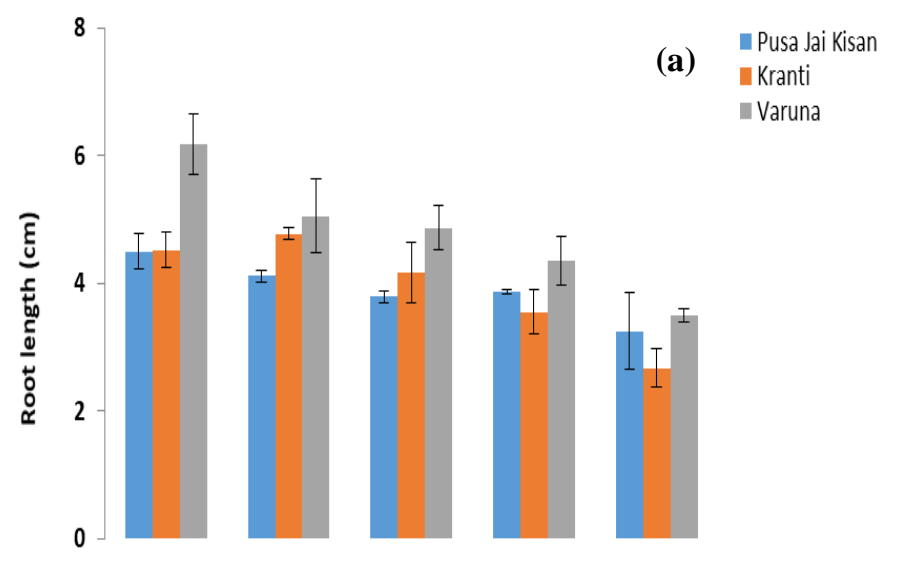

(b)
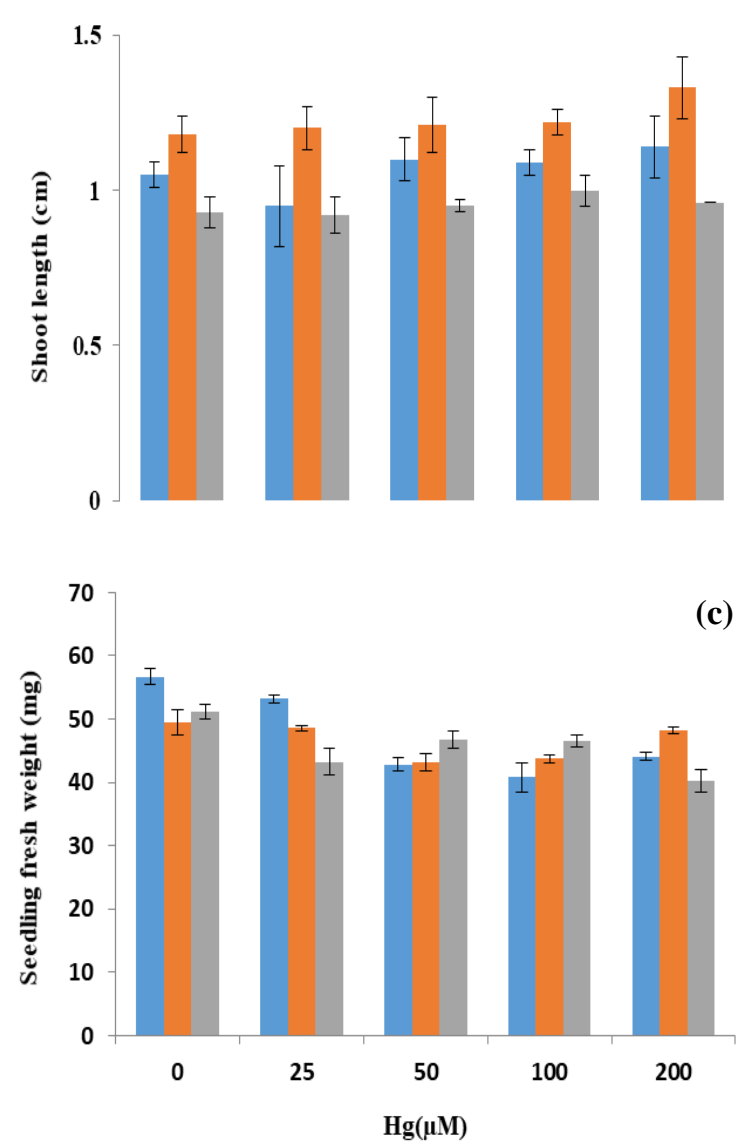

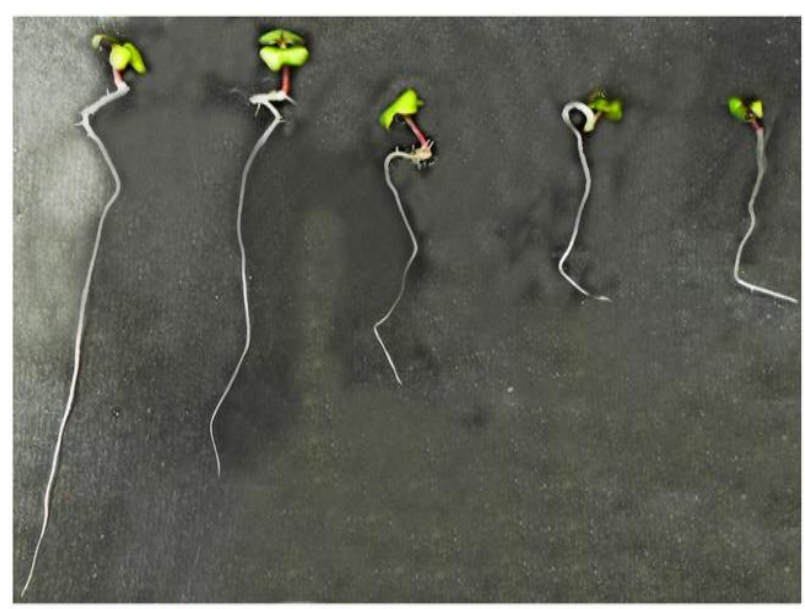

(d)

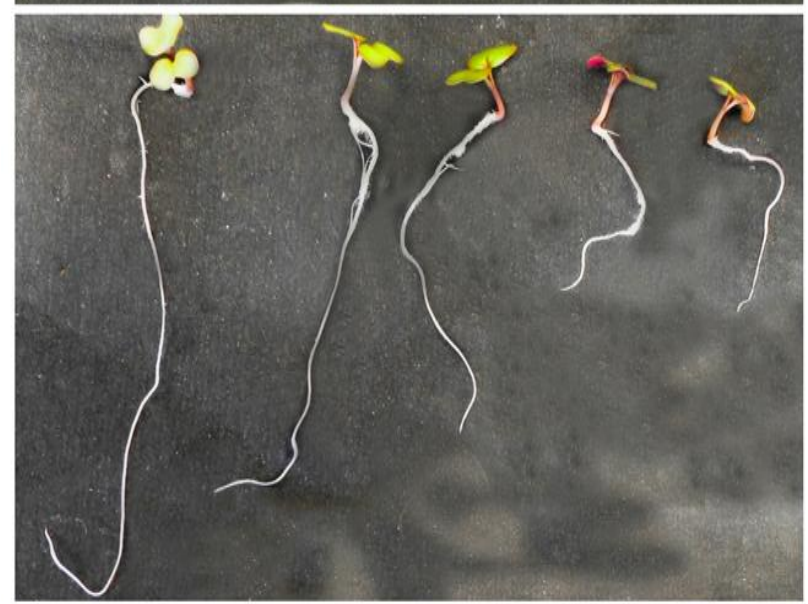

(e)

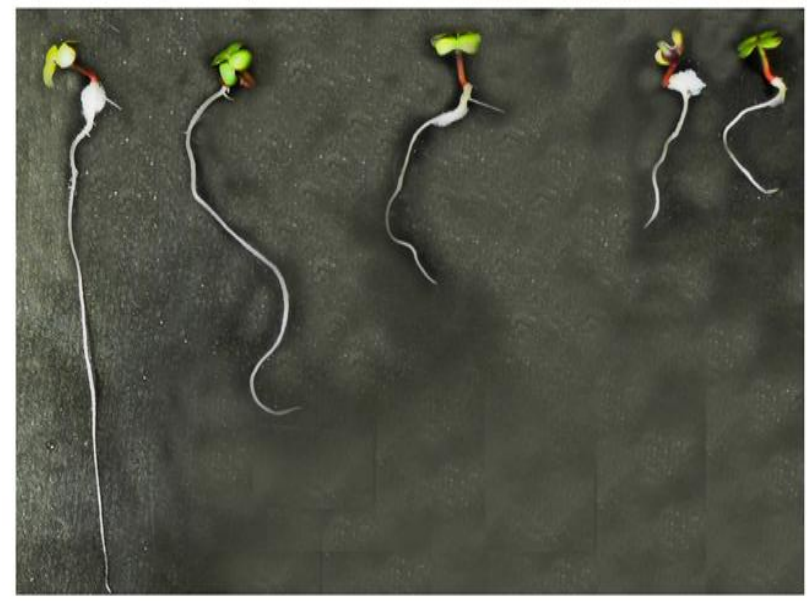

(f)

Fig.2 Effect of $\mathrm{Hg}$ on seedling growth after 6d, of different Brassica juncea cultivars, (a) Root length, (b) Shoots length, (c) seedling fresh weight. 6d-old seedlings of cvs. Pusa Jai Kisan (d), Kranti (e), and Varuna (f). Data are arithmetic means \pm S.E., $n=30$ 


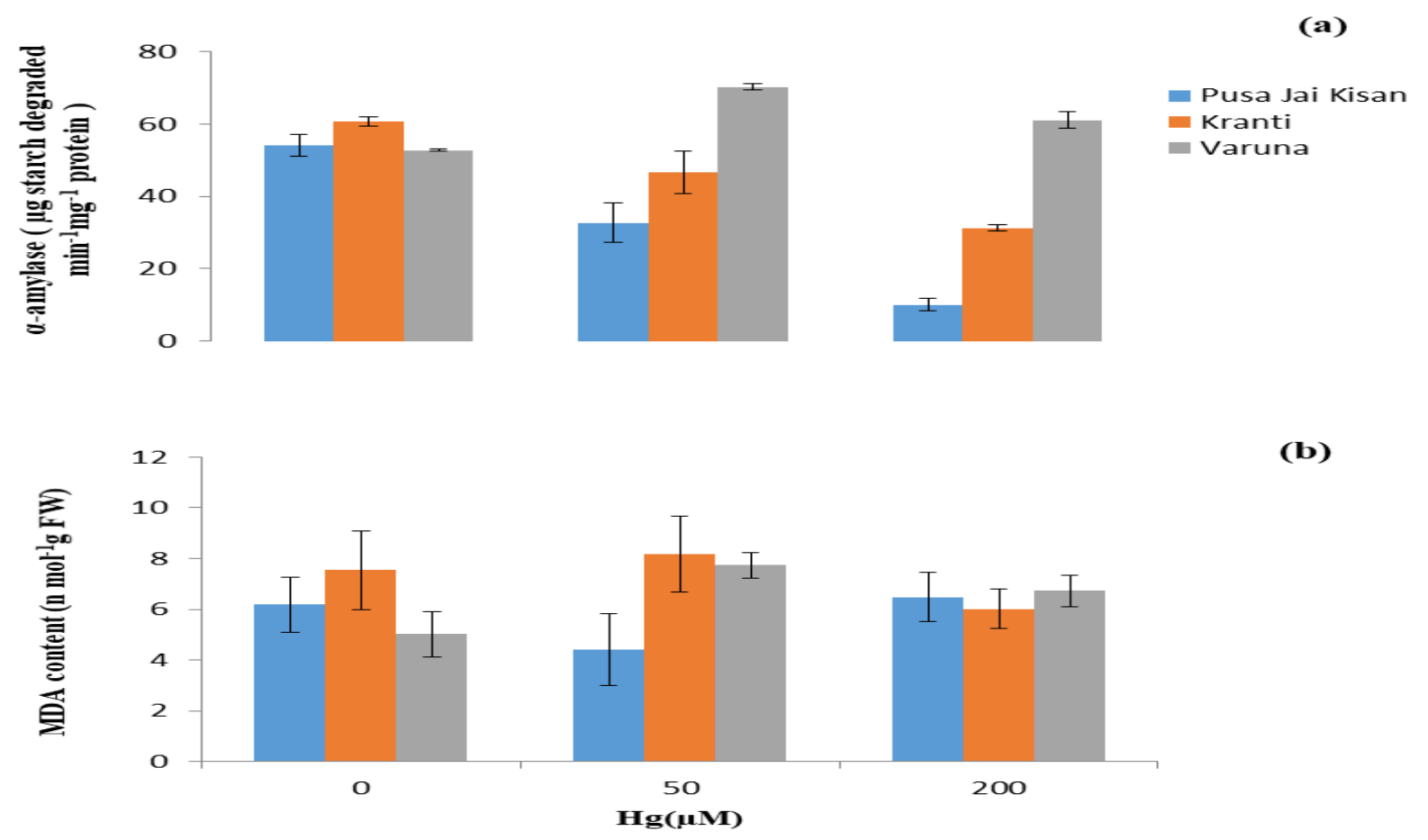

Fig.3 Effect of $\mathrm{Hg}$ ( $24 \mathrm{~h}$ treatment) on (a) $\alpha$-amylase activity and (b) lipid peroxidation in terms of MDA content in the seeds of Brassica juncea cultivars. Data are arithmetic means \pm S.E., $n=3$
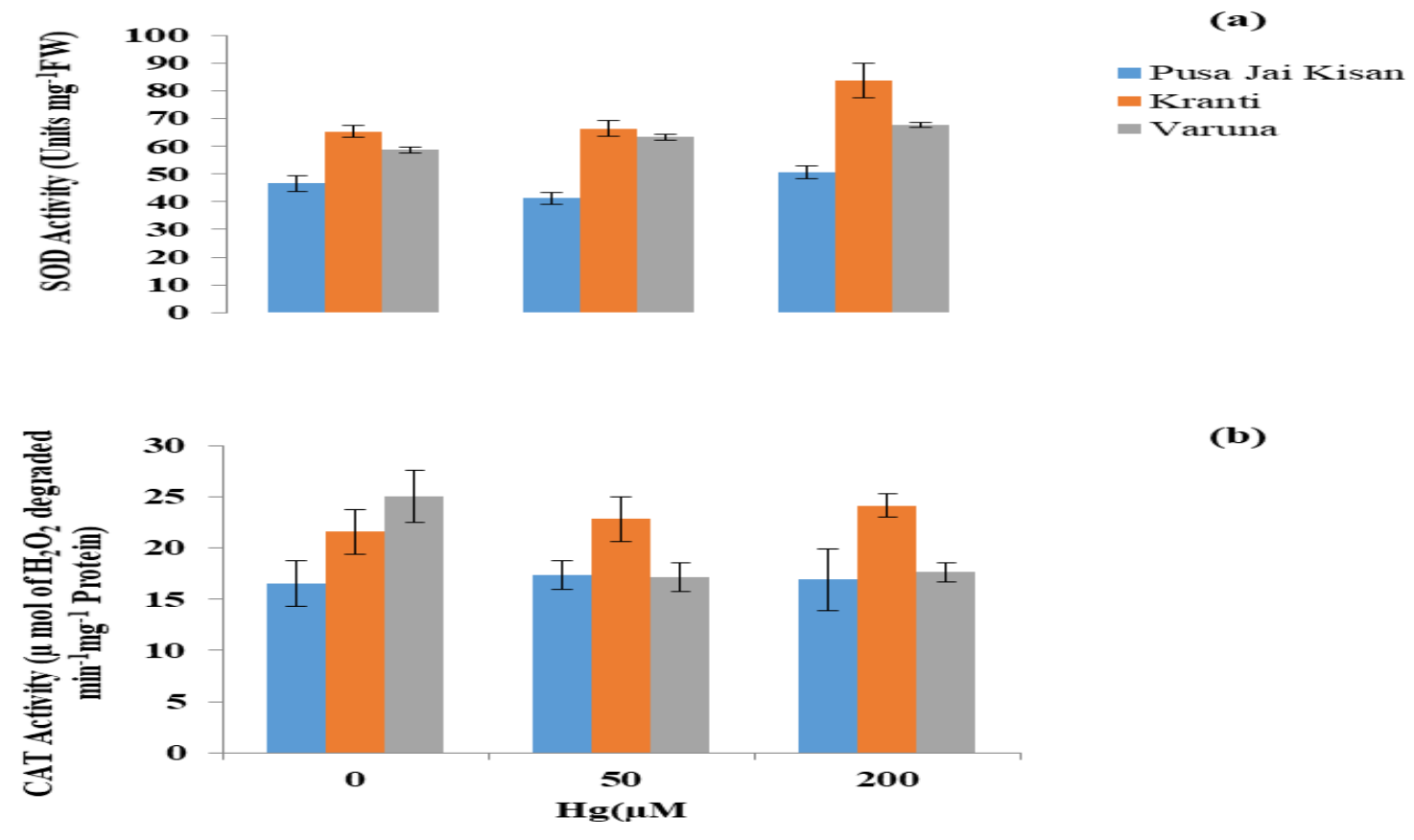

(b)

Fig.4 Effect of $\mathrm{Hg}$ (24 h treatment) on (a) SOD activity and (b) Catalase activity content in the seeds of Brassica juncea cultivars. Data are arithmetic means \pm S.E., $\mathrm{n}=3$ 
In conclusion $\mathrm{Hg}$ induced suppression of seed germination and seeding growth seems to be linked to the altered hydrolytic enzymes and redox metabolism. Findings suggest strong organ and cultivar specific differences in response of different Brassica juncea cultivars to the applied $\mathrm{Hg}$ concentrations. The differential responses of Brassica juncea cultivars to lipid peroxidation and alpha amylase activity seems to be a consequence of differential sub cellular $\mathrm{Hg}$ distribution and antioxidative defence resulting in constitutive activity of SOD and CAT. The findings have implications for establishment of seedlings in mercury rich soils which is a prerequisite for effective phytoremediation

\section{Acknowledgements}

Authors are grateful to Head, Department of Biosciences, Himachal Pradesh University Shimla, for providing necessary facilities to conduct this research work. First author is also grateful to Professor SS Sharma for their suggestions and assistance.

\section{References}

Beauchamp C, Fridovich I (1971) Superoxide dismutase: improved assays and an assay applicable to acrylamide gels. Anal Biochem. 44: 276-287.

Boening DW (2000) Ecological effects, transport, and fate of mercury: a general review. Chemosphere. 40: 1335-1351.

Cho UH, Park JO (2000) Mercury-induced oxidative stress in tomato seedlings. Plant Sci.156: 1-9.

Dhindsa RS, Plumb-Dhindsa P, Thorpe TA (1981) Leaf senescence: correlated with increased levels of membrane permeability and lipid peroxidation, and decreased levels of superoxide dismutase and catalase. J Exp Bot. 32: 93-101.

Esteban E, Moreno E, Penalosa J, Cabrero JI, Millán R, Zornoza P (2008) Short and longterm uptake of $\mathrm{Hg}$ in white lupin plants: kinetics and stress indicators. Environ Exp
Bot. 62: 316-322.

Filner P, Varner JE (1967) A test for de novo synthesis of enzymes: density labeling with $\mathrm{H}_{2} \mathrm{O}_{18}$ of barley alpha-amylase induced by gibberellic acid. Proc Natl Acad Sci USA. 58 (4): 1520.

Han FX, Su Y, Monts DL, Waggoner CA, Plodinec MJ (2006) Binding, distribution, and plant uptake of mercury in a soil from Oak Ridge, Tennessee, USA. Sci Total Environ. 368: 753-768.

Heath RL, Packer L (1968) Photoperoxidation in isolated chloroplasts: I. Kinetics and stoichiometry of fatty acid peroxidation. Arch Biochem Biophys.125: 189-198.

Jagastheeswari D, Ranganathan P (2012) Influence of mercuric chloride on seed germination, seedling growth and biochemical analysis of green gram (Vigna radiata (L.) Wilcek var. Vamban-3). Int J Pharm Biol Arch.3: 291-295.

Jeliazkova E, Crake LE, Xing B (2003) Seed germination of anise, caraway, and fennel in heavy metal contaminated solutions. $\mathbf{J}$ Herbs Spices Med Plants. 10: 83-93.

Kolker A, Senior CL, Quick JC (2006) Mercury in coal and the impact of coal quality on mercury emissions from combustion systems. Appl Geochem. 21: 1821-1836.

Kumar A, Thakur N (2019) Phytoremediation: Green technology for heavy metal clean up from contaminated soils. Int $\mathrm{J}$ Chem Stud. 7(5): 1987-1994.

Lindberg S, Bullock R, Ebinghaus R, Engstrom D, Feng X, Fitzgerald W, Seigneur C(2007) A synthesis of progress and uncertainties in attributing the sources of mercury in deposition. AMBIO: A Journal of the Human Environment.36: 19-34.

Ling T, Fangke Y, Jun R (2010) Effect of mercury to seed germination, coleoptile growth and root elongation of four vegetables. Res $\mathrm{J}$ Phytochemistry. 4: 225-233.

Liu G, Cai Y, O’Driscoll N (2011) Environmental chemistry and toxicology of mercury, John Wiley \& Sons.

Mondal NK, Das C, Datta JK (2015) Effect of mercury on seedling growth, nodulation and ultrastructural deformation of Vigna radiata (L) Wilczek." Environ Monit 
Assess. 187: 241.

Neumann D, Zur Nieden U, Schwieger W, Leopold I, Lichtenberger O (1997) Heavymetal tolerance of Minuartia verna. J Plant Physiol. 151: 101-108.

Ortega-Villasante C, Rellán-Alvarez R, Del Campo FF, Carpena-Ruiz RO, Hernández LE (2005) Cellular damage induced by cadmium and mercury in Medicago sativa. $\mathrm{J}$ Exp Bot.56: 2239-2251.

Patra M, Bhowmik N, Bandopadhyay B, Sharma A (2004) Comparison of mercury, lead and arsenic with respect to genotoxic effects on plant systems and the development of genetic tolerance. Environ Exp Bot. 52: 199-223.

Pätsikkä E, Kairavuo M, Šeršen F, Aro EM, Tyystjärvi E (2002) Excess copper predisposes photosystem II to photoinhibition in vivo by outcompeting iron and causing decrease in leaf chlorophyll. Plant Physiol. 129: 1359-1367.

Pilon-Smits E (2005) Phytoremediation. Annu Rev Plant Biol. 56: 15-39.

Rodríguez-Alonso J, Sierra MJ, Lominchar MÁ, Millán R (2019) Effects of mercury on the germination and growth of Quercus ilex $L$. seedlings. Environ Sci Puollut R. 26: 30930-30940.

Sahu GK, Upadhyay S, Sahoo BB (2012) Mercury induced phytotoxicity and oxidative stress in wheat (Triticum aestivum L.) plants. Physiol Mol Biol Pla. 18: 21-31.

Schutzendubel, Polle A (2002) Plant responses to abiotic stresses: heavy metal- induced oxidative stress and protection by mycorrhization. J Exp Bot. 53: 1351-1365.

Sharma SK, Kumar A (2015) Role of biomolecules in sensing, signal transducing and acclimation in plants against frost induced low temperature stress -A review.Int J Eng Sci Technol. 2: 21872207.

Sharma SS, Dietz KJ (2006). The significance of amino acids and amino acid-derived molecules in plant responses and adaptation to heavy metal stress. J Exp Bot. 57: 711726.

Sharma SS, Dietz KJ (2009) The relationship between metal toxicity and cellular redox imbalance. Trends Plant Sci. 14: 43-50.

Sharma SS, Kaul S, Metwally A, Goyal KC, Finkemeier I, Dietz KJ (2004) Cadmium toxicity to barley (Hordeum vulgare) as affected by varying $\mathrm{Fe}$ nutritional status. Plant Sci.166: 1287-1295.

Sierra MJ, Millán R, Esteban E (2009) Mercury uptake and distribution in Lavandula stoechas plants grown in soil from Almadén mining district (Spain). Food Chem Toxicol .47: 2761-2767.

Singh R, Gautam N, Mishra A, Gupta R (2011) Heavy metals and living systems: An overview. Indian J Pharmacol. 43: 246.

Thakur S, Sharma SS (2016) Characterization of seed germination, seedling growth, and associated metabolic responses of Brassica juncea L. cultivars to elevated nickel concentrations. Protoplasma, 253: 571-580.

Wang W, Vinocur B, Altman A (2003). Plant responses to drought, salinity and extreme temperatures: towards genetic engineering for stress tolerance. Planta. 218: 1-14.

Wierzbicka M, Obidzińska J (1998) The effect of lead on seed imbibition and germination in different plant species. Plant Sci. 137: 155171.

\section{How to cite this article:}

Ajay Kumar and Sharma, S. S. 2020. Effect of Mercury on Seed Germination, Growth Parameters and Biochemical Characteristics of Indian Mustard (Brassica Juncea L.) Cultivars. Int.J.Curr.Microbiol.App.Sci. 9(04): 1492-1502. doi: https://doi.org/10.20546/ijcmas.2020.904.176 